CENDEKIA, Vol. 11, No. 2, Oktober 2017

p ISSN: 1978 2098; e -ISSN: 2407 8557

Http://cendekia.pusatbahasa.or.id; Email: cendekiaoslo@gmail.com

Center of Language and Culture Studies, Surakarta, Indonesia

Wahidah, Kurnia Yulia Baiq, Djatmika, \& Marmanto, Sri. 2017. Alih Kode di Lingkungan

Pondok Pesantren Ulil Albaab: Kajian Sosiolinguistik Cendekia, (2017), 11(2): 143 158.

\title{
ALIH KODE DALAM INTERKASI DI LINGKUNGAN PONDOK PESANTREN ULIL ALBAAB: KAJIAN SOSIOLINGUISTIK
}

\author{
Baiq Yulia Kurnia Wahidah ${ }^{1}$, Djatmika ${ }^{2}$, Sri Marmanto ${ }^{3}$ \\ ${ }^{1}$ Penyusun Tesis Magister, ${ }^{2-3}$ Pembimbing Tesis \\ Magister Program Studi Linguistik \\ Universitas Sebelas Maret \\ JL. Ir. Sutami No 36-A Kentingan, 57126. \\ Telp. (0271) 646994/ fax: (0271) 646655. \\ Email: yuliakurnia_wahidah@yahoo.com; djatmi@yahoo.com \\ srimarmanto50@gmail.com
}

\begin{abstract}
This research describes the use of code switching in to four domains and the code switching form in the Ulil Albab boarding schools Sasak. This study applied qualitative approach and used sociolinguistics as the basis of interpretation. Subject of this study were santri and teachers in the pesantren. The primary data were observed from the classroom settings and daily activities in the pesantren, when santri and teachers spoke in four languages: Indonesian, English, Arabic, and Sasak language. Data were analyzed using as the theory of code switching and code mixing from Dell Hymes. The study revealed that code switching occured 138 tokens and conversation appeared at $75 \%$. Code switching was used as to give better comprehension to partnered-speaker.
\end{abstract}

Keywords: interaction, code switching kinds, language variation

Hakikatnya dalam kehidupan sehari-hari masyarakat menggunakan dua bahasa atau lebih (bilingual) untuk berkomunikasi sesuai dengan partisispan, topik, dan situasinya. Fenomenanya saat ini banyak dari mereka yang menguasai dua bahasa bahkan lebih, yakni bahasa pertama (bahasa ibu) dan bahasa kedua. Bahasa yang digunakan oleh masyarakat di pulau Lombok adalah bahasa Sasak. Sehingga, di lingkungan pondok pesantren Ulil Albaab juga para siswa dan guru tidak terlepas dari penggunaan bahasa Sasak sebagai bahasa ibu dan bahasa Indonesia sebagai bahasa nasional, dan bahasa asing yaitu bahasa Ingris dan bahasa Arab. Penutur masyarakat Lombok yang masih tetap mempertahankan bahasa Sasak sebagai bahasa ibu merupakan identitas daerahnya dan menganggap bahasa Sasak mempunyai peranan penting dalam kehidupan sosial budaya masyarakatnya. Sehingga, di lingkungan pondok pesantren juga siswa dan guru tidak menghilangkan identitas daerahnya dengan tetap menggunakan bahasa Sasak, fenomena ini sering ditemukan ketika para guru sedang berbicara dengan guru yang lain.

Penggunaan alih kode dapat ditemukan ketika proses berinteraksi antara dua orang atau lebih dalam berkomunikasi. Di lingkungan sebuah pondok pesantren peristiwa dalam pemilihan alih kode dapat ditemukan ketika para siswa maupun guru 
CENDEKIA, Vol. 11, No. 2, Oktober 2017

p ISSN: 1978 2098; e ISSN: 2407 8557

Http:/ / cendekia.pusatbahasa.or.id; Email: cendekiaoslo@gmail.com

Center of Language and Culture Studies, Surakarta, Indonesia

Wahidah, Kurnia Yulia Baiq, Djatmika, \& Marmanto, Sri. 2017. Alih Kode di Lingkungan

Pondok Pesantren Ulil Albaab: Kajian Sosiolinguistik

Cendekia, (2017), 11(2): 143 158.

melakukan sebuah komunikasi. Pemilihan alih kode tersebut dapat ditemukan diberbagai tempat di lingkungan pondok pesantren, mulai dari tempat tinggal para siswa, sekolah, masjid (tempat melaksanakan ibadah), kantin sekolah, aula pondok dan lain sebagainya. Adapun peristiwa alih kode dalam bentuk bahasa Indonesia dan beralih ke bahasa Sasak atau bahasa daerah dapat ditemukan ketika dua orang siswa yang sedang berkomunikasi. Di tengah-tengah percakapan mereka ada orang ketiga yaitu seorang guru yang mengajar mereka, dan serentak mereka lalu menggunakan bahasa Sasak (bahasa daerah).

Selain dari penggunaan bahasa Indonesia dan bahasa Sasak, lingkungan pondok pesantren juga menerapkan dua bahasa asing yang harus dikuasai oleh para siswa dan guru yang mengajar. Kedua bahasa asing yang dipergunakan adalah bahasa Inggris dan bahasa Arab. Bahasa Inggris dan bahasa Arab menjadi bahasa keseharian mereka juga di lingkungan pondok pesantren Ulil Albaab. Sehingga terjadilah masyarakat bilingualisme, masyarakat bilingualisme (kedwibahasaan) terjadi karena masyarakat pemakai bahasa menggunakan banyak bahasa. Peristiwa ini menunjukkan bahwa lingkungan pondok pesantren merupakan masyarakat bilingualisme dan menjadi budaya yang diterapkan pada siswa dan gurunya. Peristiwa yang menunjukkan pemakaian bahasa yang menggunakan alih kode dalam bahasa Arab dan bahasa Inggris dapat dilihat dari sebuah percakapan antara dua orang siswa yang sedang makan di kantin sekolah. Di sela-sela percakapan mereka, datanglah seorang pembina bahasa (biro bahasa) maka serentak mereka langsung menggunakan bahasa Inggris untuk berkomunikasi. Hal ini merupakan salah satu bentuk alih kode dalam bahasa Indonesia ke dalam bahasa Inggris oleh para siswa. Kejadian ini menunjukkan bentuk pelanggaran dari siswa karena pada hari itu mereka harus menggunakan bahasa Inggris.

Penelitian-penelitian tentang penggunaan sosiolinguistik telah banyak dilakukan terutama pengkajian terhadap penggunaan alih kode, akan tetapi masih terbatas pada penggunaan seperti sosial media, ceramah, atau perbincangan dari para artis. Oleh karena itu, peneliti mendapat celah untuk melakukan penelitian tentang penggunaan alih kode di lingkungan pondok pesantren yang belum pernah diteliti dari penggunaan empat bahasa, pondok pesantren yang dimaksudkan dalam penelitian ini adalah Ulil Albaab yang menggunakan empat bahasa dalam pemilihan alih kode.

Di antara penelitian-penelitian yang relevan dengan penelitian yang peneliti kaji, yaitu mengenai penelitian-penelitian yang telah ada dan termuat dalam Jurnal Internasional, Makalah dan Tesis-tesis yang telah selesai disusun. Penelitian relevan di sini dimaksud untuk membandingkan antara penelitian peneliti sendiri dengan penelitian-penelitian yang telah dilakukan.

Penelitian yang dimaksud dengan bidang kajian yang sama yang telah dilakukan. Nuken Tazikiroh Lekso (2016) Tesis berjudul " Alih Kode Dalam Pidato Tokoh Masyarakat Dalam Tradisi Swalayan Acara Pemotongan Lopis Raksasa Di Kota Pekalongan ". Penelitian ini mengkaji mengenai beberapa pemilihan alih kode yang bertujuan untuk mendeskripsikan faktor penyebab terjadinya pemilihan alih kode dalam teks pidato tokoh masyarakat swalayan di Pekalongan. Dalam penelitian ini dilihat pemilihan alih kode dalam bahasa Indonesia dengan bahasa jawa dari tingkat ngoko dan 
CENDEKIA, Vol. 11, No. 2, Oktober 2017

p ISSN: 1978 2098; e ISSN: 2407 8557

Http:/ / cendekia.pusatbahasa.or.id; Email: cendekiaoslo@gmail.com

Center of Language and Culture Studies, Surakarta, Indonesia

Wahidah, Kurnia Yulia Baiq, Djatmika, \& Marmanto, Sri. 2017. Alih Kode di Lingkungan

Pondok Pesantren Ulil Albaab: Kajian Sosiolinguistik

Cendekia, (2017), 11(2): 143 158.

krama, bahasa Arab dan bahasa Inggris. Sehingga peneliti berusaha mendapatkan jawaban dari tujuan penelitiannya yaitu menemukan faktor-faktor yang mengakibatkan terjadinya pemilihan alih kode dalam teks pidato. Penggunaan empat bahasa menjadi dasar dalam penelitian ini, di mana bahasa Indonesia menjembatani bahasa-bahasa yang lainnya. Hasil dari penelitian ini adalah, peneliti menemukan berbagai faktor yang menyebabkan terjadinya penggunaan alih kode dalam teks pidato oleh tokoh masyarakat dalam tradisi swalayan acara pemotongan lopis raksasa di kota Pekalongan. Dari adanya faktor-faktor penyebab yang ditemukan menimbulkan sebuah kesimpulan bahwa ada tujuan tersendiri dari tokoh masyarakat dalam menggunakan alih kode tersebut.

Dari penelitian yang pernahdilakukan di atas, dapat disimpulkan bahwa masingmasing mempunyai objek kajian penelitian tersendiri. Penelitian terdahulu yang berkaitan dengan penggunaan alih kode dapat dijadikan sebagai sebuah perbandingan untuk penelitian ini. Dari penelitian tersebut adanya persamaanya itu penggunaan alih kode dengan bahasa yang sama yaitu bahasa Indonesia, Arab dan Inggris. Penggunaan alih kode banyak ditemukan pada penelitian sebelumnya mengambil objek kajian pada media social seperti facebook. Selain itu juga ada ceramah dari seseorang pada saat berpidato, maupun pada arti-artis yang sering menggunakan alih kode. Perbandingan yang menunjukkan penggunaan alih kode di dalam kelas juga dapat dilihat dari beberapa penelitian terdahulu, melainkan objek kajiannya tidak berada pada lingkungan pondok pesantren. Kajian yang diambil lebih banyak pada sekolah-sekolah umum dan pada lingkungan social seperti tempat bekerja maupun pada ranah keluarga. Sehingga, penelitian ini merupakan salah satu objek dari pesantren dalam penggunaan alih kode yang dilihat dari interaksi berkomunikasi baik itu oleh siswa maupun guru. Penelitian ini melihat bagaimana siswa dan guru menggunakan empat bahasa dalam komunikasinya.

\section{Sosiolinguistik}

Sosiolinguistik adalah ilmu yang mengkaji hubungan antara bahasa dan masyarakat (Holmes 2001:1). Sosiolinguistik menjelaskan mengapa penutur bahasa menggunakan bahasa secara berbeda pada konteks sosial yang berbeda. Selain itu, sosiolinguistik juga mencoba mengidentifikasi fungsi-fungsi sosial suatu bahasa. Faktor sosial merupakan faktor yang paling penting yang melatari hubungan antara bahasa dan masyarakat. Beberapa faktor sosial tersebut berhubungan dengan pengguna bahasa, keadaan sosial, dan fungsi interaksi.

Holmes (2001:8) mengemukakan beberapa komponen yang mempengaruhi hubungan antara bahasa dengan masyarakat yaitu: (1) Partisipanya itu siapa yang berbicara dan kepada siapa mereka berbicara; (2) Latar atau konteks social suatu interaksi yaitu di mana mereka berbicara; (3) Topik yaitu apa yang sedang dibicarakan; dan (4) Fungsi yaitu mengapa mereka berbicara.

Selain itu juga dalam pandangan Richard (dalam Rahardi, 2002:3) sosiolingustik dapat diapahami sebagai "the study of language in relation to social factor, that is, social class, educational level, and type of education, age, sex, etcnich origin, etc". Sedangkan Fishman (dalam Pateda, 1987) menunjukkan bahwa "sosiolinguistics is the 
CENDEKIA, Vol. 11, No. 2, Oktober 2017

p ISSN: 1978 2098; e ISSN: 2407 8557

Http:/ / cendekia.pusatbahasa.or.id; Email: cendekiaoslo@gmail.com

Center of Language and Culture Studies, Surakarta, Indonesia

Wahidah, Kurnia Yulia Baiq, Djatmika, \& Marmanto, Sri. 2017. Alih Kode di Lingkungan

Pondok Pesantren Ulil Albaab: Kajian Sosiolinguistik

Cendekia, (2017), 11(2): 143 158.

study of the characteristic of language varieties, the characteristics of their functions, and the characteristics of their speakers as these three constanly interact, change and change another within a speech community".

Selain kedua teori di atas, Kridalaksana (dalam Rahardi, 2002) mendefinisikan sosiolinguistik sebagai cabang linguistik yang mempelajari hubungan dan saling berpengaruh antara prilaku bahasa dan perilaku sosial. Beberapa teori mengenai sosiolinguistik mendeskripsikan bahwa sosiolinguistik merupakan salah satu cabang linguistik yang mengkaji mengenai pemakaian bahasa pada masyarakat yang berbentuk variasi-variasi yang disebabkan oleh beberapa faktor. Faktor penggunaan bahasa pada umumnya dipengaruhi oleh konteks sosial maupun konteks budaya yang dimiliki masyarakat penuturnya. Penguasaan bahasa (mastery of language) menjadi salah satu bidang kajian dalam sosiolinguistik.

\section{Penggunaan Alih Kode}

Alih kode adalah penggunaan lebih dari satu bahasa oleh seorang dwibahasawan/multibahasawan yang bertutur dengan memilih salah satu kode bahasa disesuaikan dengan keadaan, seperti yang diutarakan Hudson "Any one who speaks more than one language chooses between them according to circumstance" (Hudson, 1996:51). Sedangkan Chaer, (1995:141) menjelaskan alih kode adalah berubahnya dari ragam santai menjadi ragam resmi, atau juga ragam resmi ke santai. Apple, (dalam Chaer, 1995:141) mendefinisikan alih kode sebagai "gejala peralihan pemakaian bahasa karena berubahnya situasi”. Sedangkan, Scotton (1992:2) alih kode juga terjadi ketika seseorang menghubungkan atau memasukkan bahasa keduanya ke dalam tuturan bahasa pertamanya namun masing-masing klausa dari kedua bahasa tersebut tetap mendukung fungsi bahasanya sendiri-sendiri. Nababan (1991:31) menyatakan bahwa konsep alih kode mencakup juga kejadian pada waktu kita beralih dari satu ragam bahasa yang satu ke ragam bahasa yang lain, misalnya dari ragam formal ke ragam nonformal.

Seorang yang bilingual biasanya dapat menjelaskan alasan mereka dalam beralih kode. Alasan tersebut bahwa mereka tidak memiliki sarana dalam satu bahasa ketika berbicara dalam satu topik tertentu. Bilingual usually explain that the reason they codeswitch is that they lack facility in one language when talking about particular topic (Grosjean, 1982:149). Sedangkan menurut Hudson (1996:51) Anyone who speaks more than one language chooses between them according to circumstances. Dari kedua pendapat tersebut, alih kode merupakan penggunaan dua bahasa yang dipilih oleh pemakainya sendiri.

Hymes dalam (Wardaugh,1986:238-239) merumuskan unsur-unsur pembentuk adanya kode dalam SPEAKING.

a. The setting and scene (latar dan suasana tutur), elemen yang berkaitan dengan tempat dan waktu percakapan.

b. The participant (peserta tutur), adalah orang-orang yang terlibat dalam percakapan mencakup, penutur, mitra tutur, dan orang yang berada disekitar percakapan.

c. End (tujuan tutur), adalah tujuan dan hasil percakapan. 
CENDEKIA, Vol. 11, No. 2, Oktober 2017

p ISSN: 1978 2098; e ISSN: 2407 8557

Http://cendekia.pusatbahasa.or.id; Email: cendekiaoslo@gmail.com

Center of Language and Culture Studies, Surakarta, Indonesia

Wahidah, Kurnia Yulia Baiq, Djatmika, \& Marmanto, Sri. 2017. Alih Kode di Lingkungan

Pondok Pesantren Ulil Albaab: Kajian Sosiolinguistik Cendekia, (2017), 11(2): 143 158.

d. Act squence (topik tutur), mencakup isi pesan dan bentuk pesan.

e. Key (gaya, suasana, atau tindakan), sesuatu yang menyatakan jenis percakapan; lisan maupun non lisan, nada dan gaya bahasa, serta cara menyampaikan ide, baik secara serius atau tidak.

f. Instrumentalities (instrumen percakapan), yaitu cara atau alat-alat yang digunakan dalam berkomunikasi, apakah lisan, tertulis, gerak tubuh, surat, telpon, maupun dengan yang lainnya.

g. Norm of intraction and interpretation (norma interaksi dan interpretasi), mencakup norma sikap kepatutan dalam berkomunikasi.

h. Genre (bentuk bahasa dan variasinya), mengacu pada kategori atau variasi yang digunakan atau bentuk aktivitas komunikasi yang memiliki ciri tertentu seperti pidato, novel, puisi dan lain-lain.

\section{Jenis-jenis Alih Kode}

Alih kode dapat digolongkan menjadi beberapa macam tergantung pada sudut pandang yang digunakan. Hudson (dalam Suandi, 2014:134) membagi alih kode menjadi tiga macam, yaitu methaporical code swicthing, conversational codeswitching, dan situational code switching.

\section{1) Metaphorical Code Switching}

Methaporical code switching adalah suatu gejala alih kode yang biasa menggunakan satu variasi bahasa dalam satu macam situasi, tetapi variasi bahasa itu juga digunakan dalam situasi lain, asal pokok (topik) pembicaraannya sama dengan situasi yang sama. Tujuan dari Methaporical code switching adalah untuk mempengaruhi orang lain.

Blom dan Gumperz dalam (Hudson, 1996:52) but in some cases the situation is less clear, either because it is ambiguous or because the speaker decides to ignore the observable external situation and focus instead on less observable characteristics of the people concerned. Such cases, where it is the choice of language that derermines the situation, are called Methaporical code-Switching.

\section{2) Conversational Code Switching}

Conversational code switching adalah alih kode yang digunakan untuk menyebut situasi bila seorang pembicara mungkin mengubah variasi bahasanya dalam suatu kalimat tunggal dan berbuat serupa berulang-ulang, Gumperz (dalam Suandi, 2014:134). Hudson (1996:53) menyatakan: there are other cases, however, where a fluent bilingual talking another fluent bilingual changes language without any change at all in the situation.

\section{3) Situational Code Switching}

Situational code switching adalah alih kode yang terjadi bila seseorang selalu mengganti variasi bahasanya pada setiap perubahan keadaan. Pada Conversational Code Switching pergantian semacam itu tidak ada. Situational code switching terjadi bila 
CENDEKIA, Vol. 11, No. 2, Oktober 2017

p ISSN: 1978 2098; e ISSN: 2407 8557

Http:/ / cendekia.pusatbahasa.or.id; Email: cendekiaoslo@gmail.com

Center of Language and Culture Studies, Surakarta, Indonesia

Wahidah, Kurnia Yulia Baiq, Djatmika, \& Marmanto, Sri. 2017. Alih Kode di Lingkungan

Pondok Pesantren Ulil Albaab: Kajian Sosiolinguistik

Cendekia, (2017), 11(2): 143 158.

terdapat perubahan topik, variasinya juga akan berubah sehingga menjurus ke metaphorical switching (Suandi, 2014:131).Hudson (1996:52) code switching is called situational code switching because the switches between languages always coincide with changes from one external situation. The choice of language is controlled by rules, which members of the community learn from their experience, so these rules are part of their total linguistics knowledge.

\section{METODE}

Penelitian ini menggunakan metode deskriptif kualitatif yang bertujuan untuk mendeskripsikan suatu bentuk kebahasaan yang ditentukan dalam penelitian secara apa adanya. Menurut Sutopo (2002:35) "dalam penelitian kualitatif data yang dikumpulkan terutama berupa kata-kata, kalimat atau gambar yang memiliki arti yang lebih dari pada sekedar angka atau frekuensi". Penelitian ini dimaksudkan untuk meneliti, mendeskripsikan dan menjelaskan penggunaan alih kode ketika terjadi interaksi berkomunikasi dikalangan santri di pondok pesantren Ulil Albaab berdasarkan faktafakta yang dijumpai dalam pemakaiannya. Data dianalisis dengan menggunakan pendekatan sosiolinguistik dengan mengacu pada konsep komponen tutur yang diajukan oleh Soepomo Poedjasoedarma (dalam Rustiati, 2008:69).

Dalam penelitian mengenai alih kode pada saat berinteraksi di lingkungan pondok pesantren Ulil Albaab, akan digunakan tiga tahapan strategis, yaitu tahap penyediaan data, analisis data, dan penyajian hasil analisis data. Penyediaan data dilakukan untuk mendapatkan fakta-fakta kebahasaan yang berkaitan dengan penggunaan alih kode.

Sumber data dari penelitian ini adalah guru da siswa yang berada di lingkungan pondok pesantren Ulil Albaab. Data penelitian ini berbentuk ujaran dari para siswa dan guru yang mengandung penggunaan alih kode pada saat interaksi berkomunikasi di lingkungan pondok pesantren Ulil Albaa. Metode pengambilan data menggunakan teknik observasi, sadap, rekaman dan wawancara. Teknik analisis data menggunakan metode etnografi komunikasi yaitu komponen tutur dari miliknya Dell Hymes "SPEAKING'.

\section{HASIL}

\section{Penggunaan alih kode pada beberapa ranah}

Dari hasil penelitian yang sudah dilakukan, ada empat ranah yang ditemukan untuk penggunaan alih kode yaitu pada saat interaksi berkomunikasi yang dilakukab di pondok pesantren Ulil Albaab. Ranah yang pertama adalah ranah pertemanan, pada ranah ini peneliti mengamati dan mengambil data pada para siswa ataupun santri yang sedang berkomunikasi. Ranah ini merupakan suatu ranah yang paling banyak ditemukan dalam penggunaan alih kode. Ketika mereka berkomunikasi dengan sesama temannya, ada beberapa bahasa yang dipergunakan yaitu bahasa Indonesia, Arab, Inggris, serta yang paling banyak mendominasi adalah bahasa Sasak. Para santri berkomunikasi sesuai dengan topik apa yang dibahas akan tetapi tidak monoton menggunakan satu atau 
CENDEKIA, Vol. 11, No. 2, Oktober 2017

p ISSN: 1978 2098; e ISSN: 2407 8557

Http:/ / cendekia.pusatbahasa.or.id; Email: cendekiaoslo@gmail.com

Center of Language and Culture Studies, Surakarta, Indonesia

Wahidah, Kurnia Yulia Baiq, Djatmika, \& Marmanto, Sri. 2017. Alih Kode di Lingkungan

Pondok Pesantren Ulil Albaab: Kajian Sosiolinguistik

Cendekia, (2017), 11(2): 143 158.

dua bahasa. Mereka akan lebih banyak menggunakan bahasa yang paling mudah mereka pahami, sehingga wujud alih kode yang paling banyak ditemukan adalah bahasa Sasak yaitu pada ranah pertemanan. Periksa Tabel 1.

Tabel 1. Jenis Alih Kode Ranah Pertemanan

\begin{tabular}{|c|c|c|c|c|c|c|c|c|c|}
\hline $\mathrm{N}$ & \multirow{2}{*}{$\begin{array}{l}\text { Ranah } \\
\text { Pertemanan }\end{array}$} & \multicolumn{6}{|c|}{ Variasi jenis kode } & \multirow[t]{2}{*}{$\sum$} & \multirow[t]{2}{*}{$\%$} \\
\hline & & $\mathrm{M}$ & $\%$ & $\mathrm{C}$ & $\%$ & $\mathrm{~S}$ & $\%$ & & \\
\hline 1. & Asrama & 12 & $0,36 \%$ & 16 & $0,48 \%$ & 28 & $0,48 \%$ & 56 & $1,68 \%$ \\
\hline 2. & Kelas & 2 & $0,06 \%$ & - & - & - & - & 2 & $0,06 \%$ \\
\hline 3. & Kantin & - & - & - & - & 12 & $0,36 \%$ & 12 & $0,36 \%$ \\
\hline \multicolumn{2}{|c|}{ Total } & 14 & $0,42 \%$ & 16 & $0,48 \%$ & 40 & $1,2 \%$ & 70 & $100 \%$ \\
\hline
\end{tabular}

Tabel 1 menunjukkan penggunaan alih kode pada ranah pertemanan yang dibagi menjadi tiga yaitu asrama, kelas, dan kantin. Pada asrama terdapat jenis metaphorical berjumlah 12 atau $0,36 \%$, conversational 16 atau $0,48 \%$, situational 28 atau 0,48 . Sehingga jumlah keseluruhannya adalah 56 atau 1,68\%. Di kelas terdapat jenis metaphorical 2 buah jenis alih kode atau 0,06\%. Sedangkan di kantin terdapat jenis situational yaitu 12 atau 0,36\%. Dari jumlah keseluruhannya adalah jenis metaphorical yaitu 14 atau 0,42\%, conversational 16 atau 0,48\%, dan situaional 40 atau 1,2\%. Sehingga, jumlah alih kode yang terdapat pada ranah ini adalah 70 . Jenis yang paling dominan atau paling banyak dipergunakan pada ranah ini adalah situational. Jenis ini menunjukkan ketika para siswa berinteraksi dengan temannya mereka sering merubah variasi bahasanya sesuai dengan keadaan yang ada.

Tabel 2 menunjukkan ranah pendidikan. Dalam lingkungan pendidikan ditemukan interaksi oleh guru dan siswa. Saat proses belajar mengajar guru memberikan topik bahasaanya kepada para siswa menggunakan beberapa bahasa yang memungkinkan terjadi penggunaan alih kode. Ketika menyampaikan materi, guru biasanya memulai dengan bahasa Indonesia diselingi Arab atau bahasa Inggris dengan tujuan untuk memberikan pemahaman yang lebih baik kepada siswa. Ketika antarguru melakukan interaksi mereka menggunakan variasi bahasa standar yaitu bahasa Indonesia dan bahasa Sasak atau bahasa daerah. Komunikasi di antara mereka akan berjalan secara baik apabila mereka menggunakan variasi bahasa tersebut, sehingga suasana yang mereka ciptakan semakin kondusif. Wujud alih kode yang paling banyak ditemukan pada saat guru dan guru beromunikasi adalah bahasa Sasak atau bahasa daerah. 
CENDEKIA, Vol. 11, No. 2, Oktober 2017

p ISSN: 1978 2098; e ISSN: 2407 8557

Http:/ / cendekia.pusatbahasa.or.id; Email: cendekiaoslo@gmail.com

Center of Language and Culture Studies, Surakarta, Indonesia

Wahidah, Kurnia Yulia Baiq, Djatmika, \& Marmanto, Sri. 2017. Alih Kode di Lingkungan

Pondok Pesantren Ulil Albaab: Kajian Sosiolinguistik

Cendekia, (2017), 11(2): 143 158.

Tabel 2. Jenis Alih Kode Ranah Pendidikan

\begin{tabular}{|l|l|l|l|l|l|l|l|l|l|}
\hline N & Ranah & \multicolumn{6}{|l|}{ Variasi Jenis Alih Kode } & $\sum$ & $\%$ \\
\cline { 2 - 10 } o & Pendidikan & M & $\%$ & C & $\%$ & S & $\%$ & & \\
\hline 1. & Kelas & - & - & 17 & $0,51 \%$ & - & - & 17 & $0,51 \%$ \\
\hline 2. & Kantor & 17 & $0,51 \%$ & 28 & $0,84 \%$ & - & - & 45 & $1,35 \%$ \\
\hline \multicolumn{2}{l|l}{ Jumlah } & 17 & $0,51 \%$ & 45 & $1,35 \%$ & - & - & 57 & $100 \%$ \\
\hline
\end{tabular}

Dari tabel 2 diketahui penggunaan alih kode pada ranah pendidikan dibagi menjadi dua yaitu kelas dan kantor. Di kelas jenis penggunaan alih kode yang dipergunakan adalah conversational yaitu 17 atau 0,51\%. Sedangkan di kantor jenis yang dipergunakan adalah metaphorical 17 atau $0,51 \%$, conversational 28 atau $0,84 \%$. Jumlah keseluruhannya di kantor adalah 45 atau 1,35\%. Sehingga, untuk jenis penggunaan alih kode pada ranah pertemanan ini adalah jenis metaphorical berjumlah 17 atau $0,51 \%$, conversational 45 atau $1,35 \%$. Jumlah jenis alih kode keseluruhannya adalah 57. Dari tabel di atas dapat disimpulkan bahwa jenis yang paling banyak dipergunakan pada ranah pendidikan adalah conversational. Hal ini terjadi karena ketika guru menyampaikan pelajaran di kelas sering mengganti variasi bahasa dengan perulangan-perulangan kalimat tunggal yang untuk memberikan pemahaman yang lebih baik kepada para siswa mengenai topik pelajaran yang sedang dibahas.

Tabel 3 menunjukkan data ranah keagamaan. Ranah yang ketiga adalah kegamaan, keagamaan merupakan suatu wadah yang ada di lingkungan pondok pesantren Ulil Albaab untuk memberikan kegiatan yang berisi pengajaran-pengajaran bagi semua santri untuk mempelajari agama islam. Ranah keagamaan juga ditemukan adanya penggunaan alih kode ketika berlangsungnya kelas diniah antara guru atau ustaz yang mengajar dan para santri. Para guru atau ustaz yang mengajar akan menggunakan variasi bahasa juga dengan beberapa bahasa seperti bahasa Arab sebagai bahasa pembuka, bahasa Indonesia sebagai bahasa standar, serta penggunaan bahasa Sasak sebagai suatu identitas dari masyarakat suku Sasak.

Pada ranah ini tidak hanya saat kelas diniah saja yang menggunakan alih kode, melainkan pada saat ketua yayasan menyampaikan ceramhnya yaitu pada pagi hari kamis dan jumat bagi semua santri. Beliau juga seing menggunakan variasi bahasa dan membukanya dengan bahasa Arab. Pembukaan suatu kegiatan dengan bahasa Arab ini mencerminkan identitas dari kaum muslimin ketika memulai melakukan suatu kegiatan. Sehingga, dalam pemaparannya mengenai suatu topik yang sedang dibahas seringkali ada perulangan-perulangan dengan menggunakan alih kode. Tujuannya adalah untuk memberikan pemahaman yang lebih baik lagi bagi para santrinya mengenai topik apa yang sedang beliau sampaikan. 
CENDEKIA, Vol. 11, No. 2, Oktober 2017

p ISSN: 1978 2098; e ISSN: 2407 8557

Http:/ / cendekia.pusatbahasa.or.id; Email: cendekiaoslo@gmail.com

Center of Language and Culture Studies, Surakarta, Indonesia

Wahidah, Kurnia Yulia Baiq, Djatmika, \& Marmanto, Sri. 2017. Alih Kode di Lingkungan

Pondok Pesantren Ulil Albaab: Kajian Sosiolinguistik

Cendekia, (2017), 11(2): 143 158.

Tabel 3. Jenis Alih Kode Pada Ranah Keagamaan

\begin{tabular}{|c|c|c|c|c|c|c|c|c|c|}
\hline \multirow{2}{*}{$\begin{array}{l}\mathrm{N} \\
\mathrm{o}\end{array}$} & \multirow{2}{*}{$\begin{array}{l}\text { Ranah } \\
\text { Keagamaan }\end{array}$} & \multicolumn{6}{|c|}{ Variasi Jenis Alih Kode } & \multirow[t]{2}{*}{$\sum$} & \multirow[t]{2}{*}{$\%$} \\
\hline & & $\mathrm{M}$ & $\%$ & $\mathrm{C}$ & $\%$ & $\mathrm{~S}$ & $\%$ & & \\
\hline 1. & Kelas Diniah & - & - & 12 & $0,36 \%$ & - & - & 12 & $0,36 \%$ \\
\hline 2. & Pengajian Pagi & - & - & 18 & $0,54 \%$ & - & - & 18 & $0,54 \%$ \\
\hline \multicolumn{2}{|c|}{ Jumlah } & - & - & 30 & $0,9 \%$ & - & - & 30 & $100 \%$ \\
\hline
\end{tabular}

Dari tabel 3 dapat dilihat penggunaan jenis penggunaan alih kode pada ranah keagamaan dibagi menjadi dua yaitu kelas diniah dan pengajian pagi. Pada kelas diniah adanya jenis alih kode conversational yaitu 12 atau $0,36 \%$ dan pengajian pagi yaitu 18 atau $0,54 \%$. Jumlah keseluruhan dari hasil jenis penggunaan alih kode pada ranah keagamaan ini adalah 30 . Pada ranah ini jenis alih kode yang dipergunakan hanya ada satu yaitu conversational. Hal ini menunjukkan bahwa seorang guru maupun seorang yang menyampaikan ceramahnya di depan para santri sering mengganti variasi bahasa yang bertujuan untuk memberikan penekanan terhadap kalimat-kalimat tunggal untuk memberikan penjelasan yang lebih baik kepada para santri.

Tabel 4 ialah ranah pekerjaan sebagai ranah keempat. Ranah ini dapat ditemukan pada lingkungan pondok pesantren Ulil Albaab yaitu di SMA Ulil Albaab. Ranah pekerjaan merupakan suatu ranah bagi para karyawan sekolah. Ketika guru maupun siswa berkomunikais dengan karywan yang ada, maka ditemukan adanya penggunaan alih kode. Wujud penggunaan alih kode ditemukan dalam bahasa Sasak. Hal ini mencerminkan penggunaan alih kode yang selalu menggunakan bahasa mereka dan untuk mempertahankan bahasa yang dimiliki. Selain itu juga dalam penggunaan bahasa Sasak atau bahasa daerah adanya penggunaan dialek yang melihat strata penggunaannya, wujud ini bertujuan untuk menghormati lawan penuturnya.

Tabel 4. Jenis Alih Kode Pada Ranah Pekerjaan

\begin{tabular}{|l|l|l|l|l|l|l|l|l|l|}
\hline \multirow{2}{*}{ No } & Ranah & \multicolumn{9}{|l|}{ Variasi Jenis Alih Kode } & \multirow{2}{*}{ Pekerjaan } & $\%$ \\
\cline { 2 - 9 } & M & $\%$ & $\mathrm{C}$ & $\%$ & $\mathrm{~S}$ & $\%$ & & \\
\hline 1. & Kantor & 4 & $0,12 \%$ & 5 & $0,15 \%$ & - & - & 9 & $0,27 \%$ \\
\hline \multicolumn{2}{|l|}{ Jumlah } & 4 & $0,12 \%$ & 5 & $0,15 \%$ & - & - & 9 & $100 \%$ \\
\hline
\end{tabular}

Dari tabel 4 diketahui penggunaan alih kode pada ranah pekerjaan menggunakan metaphorical yaitu 4 atau $0,12 \%$ dan conversational 5 atau $0,15 \%$. Sehingga, jumlah keseluruhannya adalah 9. Dari penggunaan jenis di atas menunjukkan bahwa jenis alih kode ini adalah yang paling sedikit dalam penggunaannya. Hal ini karena intensitas dari interaksi dengan karyawan tidak sering dilakukan jika dibandingkan dengan siswa maupun guru.

Keempat tabel di atas yang menunjukkan jenis penggunaan alih kode pada saat berinteraksi di lingkungan pondok pesantren Ulil Albaab yang menunjukkan paling 
CENDEKIA, Vol. 11, No. 2, Oktober 2017

p ISSN: 1978 2098; e ISSN: 2407 8557

Http:/ / cendekia.pusatbahasa.or.id; Email: cendekiaoslo@gmail.com

Center of Language and Culture Studies, Surakarta, Indonesia

Wahidah, Kurnia Yulia Baiq, Djatmika, \& Marmanto, Sri. 2017. Alih Kode di Lingkungan

Pondok Pesantren Ulil Albaab: Kajian Sosiolinguistik

Cendekia, (2017), 11(2): 143 158.

dominan adalah ranah pertemanan. Hal ini terjadi karena siswa lebih banyak berinteraksi dengan temannya dibandingkan dengan guru maupun karyawan.

Untuk mengkalisfikasikan jenis penggunaan alih kode pada empat ranah yang ada yaitu pertemanan, pendidikan, keagamaan, dan pekerjaan disajikan hasil analisis pada Tabel 5.

Tabel 5. Hasil Rekapitulasi Klasifikasi Jenis Alih Kode

\begin{tabular}{|c|c|c|c|c|c|c|c|c|c|}
\hline \multirow[t]{2}{*}{ No } & \multirow[t]{2}{*}{ Ranah } & \multicolumn{6}{|c|}{ Jenis Alih Kode } & \multirow[t]{2}{*}{$\sum$} & \multirow[t]{2}{*}{$\%$} \\
\hline & & $\mathrm{M}$ & $\%$ & $\mathrm{C}$ & $\%$ & $\mathrm{~S}$ & $\%$ & & \\
\hline 1. & Pertemanan & 14 & $0,42 \%$ & 16 & $0,48 \%$ & 40 & $\begin{array}{l}1,6 \\
\%\end{array}$ & 70 & $\begin{array}{l}2,8 \\
\%\end{array}$ \\
\hline 2. & Pendidikan & 17 & $0,68 \%$ & 45 & $1,8 \%$ & - & - & 57 & $\begin{array}{l}2,48 \\
\%\end{array}$ \\
\hline 3. & Keagamaan & - & - & 30 & $1,2 \%$ & - & - & 30 & $\begin{array}{l}1,2 \\
\%\end{array}$ \\
\hline 4. & Pekerjaan & 4 & $0,16 \%$ & 5 & $0,2 \%$ & - & - & 9 & $\begin{array}{l}0,36 \\
\%\end{array}$ \\
\hline \multicolumn{2}{|c|}{ Jumlah } & 35 & $1,4 \%$ & 96 & $3,84 \%$ & 40 & $1,6 \%$ & 166 & $\begin{array}{l}100 \\
\%\end{array}$ \\
\hline
\end{tabular}

Dari tabel 5 diketahui penggunaan jenis alih kode pada ranah pertemanan yang metaphorical berjumlah 14 atau 0,42\%, conversational 16 atau $0,48 \%$, dan situational 40 atau 1,6\%. Sehingga jumlah keseluruhan pada ranah ini adalah 68 atau 2,72\%. Ranah pendidikan yang menunjukkan jenis metaphorical berjumlah 17 atau $0,68 \%$, conversational 45 atau 1,8\%. Jumlah keseluruhan pada ranah pendidikan adalah 62 atau $2,48 \%$. Ranah keagamaan hanya ditemukan satu buah jenis alih kode yaitu conversational berjumlah 30 atau 1,2\% dan menunjukkan jumlah keseluruhan dari ranah keagamaan. Sedangkan untuk ranah pekerjaan adanya jenis alih kode metaphorical 4 atau $0,16 \%$, conversational 5 atau $0,2 \%$. Untuk jumlah keseluruhan dari penggunaan alih kode pada ranah pekerjaan adalah 9 atau $0,36 \%$. Setelah melihat penggunaan jenis alih kode pada masing-masing ranah dapat diketahui penggunaan jenis metaphorical secara keseluruhan berjumlah 37 atau 1,48\%, conversational 96 atau 3,84\%, dan situational 40 atau 1,6\%. Dari hasil rekapitulasi ini dapat ditemukan penggunaan alih kode dalam jenis conversational yang paling dominan atau paling banyak dipergunakan ketika siswa, guru, maupun karyawan berinteraksi di lingkungan pondok pesantren Ulil Albaab.

\section{Jenis penggunaan alih kode}

Untuk menemukan jenis dari alih kode yang digunakan pada saat interaksi berkomunikasi di lingkungan pondok pesantren Ulil Albaab akan dilihat dari beberapa ranah yang ada. Jenis alih kode yang dipergunakan ada tiga jenis yaitu Metaphorical, Conversational, dan Situational. dari ketiga jenis ini akan dirincikan beberapa data yang menunjukkan penggunaan alih kode dari masing-masing jenis alih kode tersebut. 
CENDEKIA, Vol. 11, No. 2, Oktober 2017

p ISSN: 1978 2098; e -ISSN: 2407 8557

Http://cendekia.pusatbahasa.or.id; Email: cendekiaoslo@gmail.com

Center of Language and Culture Studies, Surakarta, Indonesia

Wahidah, Kurnia Yulia Baiq, Djatmika, \& Marmanto, Sri. 2017. Alih Kode di Lingkungan

Pondok Pesantren Ulil Albaab: Kajian Sosiolinguistik

Cendekia, (2017), 11(2): 143 158.

012 P1 : saas alukum al ibu ala asilati assalamualaikumwaalaikumussalam alyauma ha zal yaum (untuk kalian semua saya akan mengucapkan salam assalamualaikum jawabannya adalah waalaikumussalam, mengenai hari, hari ini hari apa?) (PEN/BI/C/N012)

015 P2 : alyaumal kamis (hari ini adalah hari kamis) (PEN/BA/C/N015)

016 P1 :summa al haqiqah nahnu ha zal yaum (selanjutnya, untuk kalian semua hari ini hari?) (PEN/BA/C/N016)

016 P2 : al yaum ha zal yaum yaumul kamis (hari ini adalah hari kamis)

Data di atas menunjukkan proses belajar mengajar di dalam kelas pada saat guru sedang menerangkan materi bahasa Arab. Setiap kali guru mengulangi beberapa kalimat tunggal yang berbentuk bahasa Arab. Pada saat itu guru sedang membahas mengenai al yaum yang artinya hari. Setiap kali guru menyampikan materinya ia merubah variasi bahasanya dengan menggunakan bahasa Arab. Tujuannya adalah agar siswa lebih mampu memahami apa yang dimaksud dengan topik hari dalam bahasa Arab. Data yang menunjukkan jenis metaphorical adalah sebagai berikut:

019 P2 Pak Mursidin : Tiang gumene tiang beli lime, lime bedoente lime tesinggak, lime jeri telang (saya sengaja saya membeli lima, lima yang kita punya lima yang dipinjam, lima jadinya yang hilang) (PEN/BS/M/N019)

020 P1 Pak Rajab $\quad$ : Be. . ngendeng laguk sik tekene ngendeng ndekne semel (itu tapi yang diminta yang dibilang kalau minta dia akan malu)

021 P2 Pak Bilal : : Ye angkak (itu makanya)

022 P1 Pak Mursidin : Sehingga orang-orang ne demen ne doang (dia si suka saja) (PEN/BS/M/N022)

Percakapan di atas menunjukkan adanya tujuan untuk mempengaruhi dari penutur pertama kepada mitra tutur. Topik yang dibahas adalah mengenai pembelian kabel. Penutur menceritakan bahwa ia selalu membeli kabel sendiri agar tidak susah mencari, namun kabel tersebut selalu hilang. Sehingga, mitra tutur dapat merespon apa yang ia sampaikan dan mengakui memang selalu ada barang-barang yang hilang di sana. Dari percakapan penutur tersebut membuat mitra tutur untuk tidak mau membeli kabel, karena ia takut kejadian serupa akan terjadi padanya. Sehingga, dari percakapan 
CENDEKIA, Vol. 11, No. 2, Oktober 2017

p ISSN: 1978 2098; e ISSN: 2407 8557

Http://cendekia.pusatbahasa.or.id; Email: cendekiaoslo@gmail.com

Center of Language and Culture Studies, Surakarta, Indonesia

Wahidah, Kurnia Yulia Baiq, Djatmika, \& Marmanto, Sri. 2017. Alih Kode di Lingkungan

Pondok Pesantren Ulil Albaab: Kajian Sosiolinguistik

Cendekia, (2017), 11(2): 143 158.

ini terdapat hubungan mempengaruhi antara penutur. Data yang menunjukkan penggunaan jenis alih kode situational adalah:

$231 \mathrm{P1} \quad$ : Te jajah no malik (D bohongi itu lagi)

232 P2 : Yoh bisa jadi (PRT/BI/S/N232)

233 P1 : Aneh ye unin, aneh lime ratus ribu bayangkan yak saling gacek $n u$, lamun bani gacek jak, nu saling gacek nu. Bareh buk lawan polisi-polisi. ( itu yang dibilang, bayangkan ada 500.000 yang akan saling membunuh, kalau memang berani membunuh tapi, mereka akan saling membunuh nantinya, nanti mereka juga akan melawan polisi-polisi). (PRT/BS/S/N233)

234 P2 : Misal lamun langan gegeklah nane, tegacek langan perian, terus laun tegacek sik peseng, perang wah. (Seandaimya nanti dari Gegek, membunuh yang dari Perian, terus nanti yang dari Peseng, akan terjadi perang sudah). (PRT/BS/S/N234)

$235 \mathrm{P} 1 \quad$ : Lemak pokok Lombok ne yak malik perang kari sekali, ye prediksi.( Besok pokoknya Lombok ini akan terjadi perang tinggal sekali, itu prediksinya).

236 P3 : Kan itu wasiat bapak Maulana Syaikh (PRT/BI/S/N236)

\section{Faktor-faktor penyebab terjadinya penggunaan alih kode}

Setelah peneliti melakukan penelitian selama beberapa bulan yang lalu, ada beberapa penyebab terjadinya penggunaan alih kode di lingkungan pondok pesantren Ulil Albaab yaitu pada saat interaksi berkomunikasi oleh siswa maupun guru dan karyawan. Adapun faktor-faktor yang menyebabkan terjadinya penggunaan alih kode mencakup:

1) Terjadinya perubahan topik pembicaraan pada saat penutur dan mitra tutur melakukan komunikasi sehingga mitra tutur menggunakan variasi bahasa yang lainnya.

2) Pada saat penutur dan mitra tutur melakukan interaksi berkomunikasi adanya kehadiran orang ke tiga dan menyebabkan variasi bahasa menjadi berubah atau adanya penggunaan alih kode.

3) Pada saat penutur menyampaikan pelajaran di kelas terjadinya pengulangan katakata pada kalimat tunggal yang bertujuan untuk memberikan pemahaman yang lebih kepada para santri maupun siswa.

4) Pada saat penutur melakukan interaksi berkomunikasi adanya perubahan variasi dialek disebabkan adanya mitra tutur yang dianggap orang yang disegani atau dihormati sehingga para penutur yang tadi akan menggunakan variasi dialek yang lebih tinggi. 
CENDEKIA, Vol. 11, No. 2, Oktober 2017

p ISSN: 1978 2098; e ISSN: 2407 8557

Http://cendekia.pusatbahasa.or.id; Email: cendekiaoslo@gmail.com

Center of Language and Culture Studies, Surakarta, Indonesia

Wahidah, Kurnia Yulia Baiq, Djatmika, \& Marmanto, Sri. 2017. Alih Kode di Lingkungan

Pondok Pesantren Ulil Albaab: Kajian Sosiolinguistik

Cendekia, (2017), 11(2): 143 158.

5) Para siswa akan menggunakan bahasa mereka sesuai dengan keadaan yang mereka hadapi, salah satu faktor ini juga berkaitan dengan kemampuan dari para siswa dalam menguasai empat bahasa yang ada di lingkungan pondok pesantren Ulil Albaab.

6) Dalam menyampaikan mata pelajaran bahasa di lingkungan pondok pesantren Ulil Albaab guru akan menggunakan dua bahasa bahkan lebih yang disebabkan karena guru tersebut mempunyai kompetensi yang lebih baik dalam penguasaan empat bahasa tersebut dan bertujuan untuk melatih para siswanya untuk dapat memahami empat bahasa yang ada.

\section{BAHASAN}

Penggunaan alih kode di lingkungan pondok pesantren Ulil Albaab mempunyai empat ranah yaitu pendidikan, keagamaan, pertemanan, dan pekerjaan. Dari ke empat ranah tersebut dapat ditemukan adanya jenis penggunaan alih kode yaitu metaphorical, conversational, dan situational. Pondok pesantren ini merupakan salah satu dari bentuk masyarakat multilingual (keanekaragaman berbahasa) ketika berkomunikasi baik itu oleh siswa dan guru maupun karyawan yang ada di lingkungan tersebut. Wujud bahasa yang sering dipergunakan dalam berkomunikasi adalah Indonesia, Arab, Inggris, dan Sasak (bahasa daerah).

Dari empat bahasa yang dipergunakan sudah memenuhi syarat untuk digolongkan ke dalam multilingual (keanekaragaman berbahasa) karena sudah menggunakan lebih dari dua bahasa pada saat berkomunikasi dengan partisipan. Dari semua ranah yang ada empat bahasa ini selalu dipergunakan dengan memilih variasi kode pada saat penutur melakukan komunikasi dengan mitra tutur. Sebab pemilihan wujud bahasa juga dapat mempengaruhi variasi kode yang digunakan. Sejalan dengan pendapat para pakar linguistik yang menyatakan bahwa multilingualisme atau keanekabahasaan yaitu penggunaan bahasa lebih dari dua bahasa (bahasa banyak) dalam berkomunikasi sehari-hari maupun dalam bertutur (Suandi, 2014:12). Jadi, sebuah pondok pesantren dapat dikatakan sebagai masyarakat multilingual (keanekabahasaan) apabila sudah menggunakan lebih dari dua bahasa pada saat berkomunikasi sehari-hari yaitu oleh siswa dan guru.

Dengan demikian, hasil analisis penggunaan alih kode di pondok pesantren Ulil Albaab yang dilihat dari empat ranah yaitu pendidikan, keagamaan, pertemanan, dan pekerjaan dapat disimpulkan bahwa, untuk memenuhi sebuah penggunaan alih kode tidak terlepas dari adanya pemakaian wujud bahasa yang merupakan keterkaitan dari variasi kode yang dipergunakan. Sehingga, dalam analisis penggunaan alih kode wujud pemakaian bahasa tersebut menentukan variasi kode yang akan dipergunakan.

Dari pemakaian bentuk alih kode di lingkungan pondok pesantren Ulil Albaab dari empat ranah yang ada ditemukan adanya jenis-jenis alih kode yaitu metaphorical, converstional, dan situational. 
CENDEKIA, Vol. 11, No. 2, Oktober 2017

p ISSN: 1978 2098; e ISSN: 2407 8557

Http://cendekia.pusatbahasa.or.id; Email: cendekiaoslo@gmail.com

Center of Language and Culture Studies, Surakarta, Indonesia

Wahidah, Kurnia Yulia Baiq, Djatmika, \& Marmanto, Sri. 2017. Alih Kode di Lingkungan

Pondok Pesantren Ulil Albaab: Kajian Sosiolinguistik

Cendekia, (2017), 11(2): 143 158.

\section{SIMPULAN}

Penggunaan alih kode dalam interaksi di lingkungan pondok pesantren Ulil Albaab menurut kajian sosiolinguistik dapat disimpulkan bahwa ketiga bentuk alih kode dipergunakan oleh partisipan yaitu siswa dan guru di berbagai ranah.

1) Sebagai sebuah pondok pesantren yang menggunakan empat bahasa ketika berkomunikasi sehari-hari bagi para siswa dan guru menimbulkan penggunaan alih kode dengan memilih variasi-variasi bahasa yang sesuai ketika berinterakasi. Penggunaan alih kode yang paling dominan berada pada ranah pertemanan yaitu 150 dengan penggunaan jenis alih kode metaphorical sebanyak 12, conversational sebanyak 16, dan situational 40. Untuk wujud variasi bahasa yang dipergunakan adalah didominasi oleh bahasa Sasak sebanyak 38, bahasa Arab 1, bahasa Inggris 19, dan bahasa Indonesia 17.

2) Di lingkungan pondok pesantren Ulil Albaab ditemukan jenis-jenis penggunaan alih kode yaitu metaphorical, conversational, dan situational. Jenis alih kode metaphorical ditemukan pada semua ranah yaitu sejumlah 35, sedangkan situational hanya pada ranah pertemanan yakni 40 dan conversational ditemukan pada tiga ranah yaitu pendidikan, keagamaan, dan pekerjaan sejumlah 91 jenis. Sehingga, jenis yang paling dominan pada penggunaan alih kode saat siswa dan guru maupun karyawan berinteraksi di lingkungan pondok pesantren Ulil Albaab adalah conversational. Jenis conversational merupakan yang paling banyak ditemukan karena adanya tujuan dari penutur untuk memberikan pemahaman yang lebih mendalam tentang apa yang disampaikan. Sehingga, mitra tutur akan lebih mudah ketika menerima apa yang disampikan.

3) Beberapa faktor yang menunjukkan penyebab terjadinya penggunaan alih kode di lingkungan pondok pesantren Ulil Albaab dalam interaksi para siswa, guru, maupun karyawan adalah: perubahan topik, kehadiran orang ke tiga, meningkatkan pemahaman bagi santri, adanya mitra tutur, kemampuan guru dalam berbahasa, dan kompetensi guru dalam menguasai empat bahasa

\section{DAFTAR PUSTAKA}

Chaer, Abdul, Agustina. \& Leonie. 2010. Sosiolinguistik Perkenalan Awal. Jakarta: PT Asdi Mahasatya.

Holmes. Janet.2001. An Introduction to Sociolinguistics 2nd edition.Longman.

Hymes. Dell. 1889. Foundation In Sosiolinguistic An Ethnographic Approach. Philandelpia: University of Pennsylvania Press.

Moleong, Lexy. J. 2014. Metodologi Penelitian Kualitatif. Bandung: PT Remaja Rosdakarya.

Miles, B. Mathew. 1986.Qualittaive Data Analysis: A Sourcebook of New Methods Beverly Hilss Sage Peblication.

Nababan pwj. 1991. Sosiolinguistik Suatu Pengantar. Jakarta: PT Gramedia Pustaka Umum.

R.A Hudson. 1996. Sociolinguistics Second Edition. Cambridge University Press. 
CENDEKIA, Vol. 11, No. 2, Oktober 2017

p ISSN: 1978 2098; e ISSN: 2407 8557

Http://cendekia.pusatbahasa.or.id; Email: cendekiaoslo@gmail.com

Center of Language and Culture Studies, Surakarta, Indonesia

Wahidah, Kurnia Yulia Baiq, Djatmika, \& Marmanto, Sri. 2017. Alih Kode di Lingkungan

Pondok Pesantren Ulil Albaab: Kajian Sosiolinguistik

Cendekia, (2017), 11(2): 143 158.

Rahardi, Kunjana. 2010. Kajian Sosiolinguistik Ihwal Alih Kode dan Campur

Kode. Bogor: Ghalia Indonesia.

Santosa, Riyadi. 2014. Metode Penelitian Kualittaif. Surakarta: UNS Press.

Scotton, Carol Myers. 1998. The Handbook Of Sociolinguistics. Coulmas Florian (ed). Oxford: Black Well

Suandi. Nengah. 2014. Sosiolinguistik. Yogyakarta: Graha Ilmu

Sutopo, H.B.2002.Metodologi penelitian kualitatif:Dasar teori dan terapannya dalam penelitian (Qualitative reseach methodology: Basic theories and their application to reseach). Surakarta: Sebelas Maret University Press.

Suwito, 1983. Pengantar Awal Sosiolinguistik Teori dan Problema. Surakarta: Henary Offset 
CENDEKIA, Vol. 11, No. 2, Oktober 2017

p ISSN: 1978 2098; e ISSN: 2407 8557

Http://cendekia.pusatbahasa.or.id; Email: cendekiaoslo@gmail.com

Center of Language and Culture Studies, Surakarta, Indonesia

Wahidah, Kurnia Yulia Baiq, Djatmika, \& Marmanto, Sri. 2017. Alih Kode di Lingkungan

Pondok Pesantren Ulil Albaab: Kajian Sosiolinguistik

Cendekia, (2017), 11(2): 143 158. 